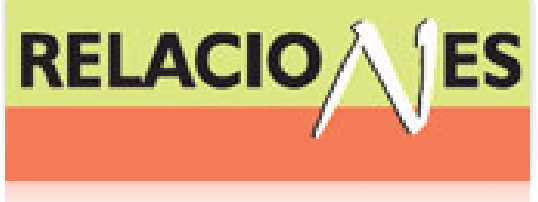

Relaciones. Estudios de historia y sociedad ISSN: 0185-3929

relacion@colmich.edu.mx

El Colegio de Michoacán, A.C

México

Spinoso Arcocha, Rosa María

Esclavitud en Minas Gerais, Araxá, 1824-1888. Fuentes notariales y demográficas

Relaciones. Estudios de historia y sociedad, vol. XXXII, núm. 127, 2011, pp. 21-45

El Colegio de Michoacán, A.C

Zamora, México

Disponible en: http://www.redalyc.org/articulo.oa?id=13719806002

Cómo citar el artículo

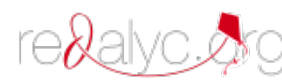

- Número completo

- Más información del artículo

- Página de la revista en redalyc.org

Sistema de Información Científica

Red de Revistas Científicas de América Latina, el Caribe, España y Portugal Proyecto académico sin fines de lucro, desarrollado bajo la iniciativa de acceso abierto 


\title{
Esclavitud en Minas Gerais, Araxá, 1824-1888. Fuentes notariales y demográficas
}

\author{
Rosa María Spinoso Arcocha* \\ UNIVERSIDAD DE GUADALAJARA/CULAGOS
}

El artículo propone una lectura cualitativa de la esclavitud negra en Araxá, Minas Gerais, Brasil, con base en la documentación proveniente del padrón Mappa Populacional da Provincia de Minas Gerais, de 1832, y de los archivos judiciales y notariales locales. La idea es adentrar en las prácticas y representaciones esclavistas en la vida cotidiana, con apoyo de la bibliografía pertinente, e indicar posibilidades temáticas para futuras investigaciones.

(Esclavitud, libertad, historia local y regional, Araxá, Brasil)

\section{Notas PRELIMiNARES}

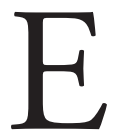

lartículo presenta un panorama tentativo de la población de origen africano en Araxá, en el actual estado y antes provincia de Minas Gerais, Brasil, y de las prácticas esclavistas en el siglo Xix. Se basa en los datos arrojados por el Mappa Populacional da Provincia de Minas Gerais, de 1832, complementado por la documentación proveniente de los archivos notariales, así como de los inventarios y testamentos del Fôrum Tito Fulgêncio, sede del Poder Judicial local, usados para ejemplificarlos. Y digo tentativo porque el tema de la esclavitud en Araxá no ha sido trabajado, ni sus procesos históricos en general. Mucho habría que hacer aún en ese sentido, por lo que agotarlo dentro de los límites de un artículo sería imposible. Igual sería prematuro abordar a fondo aspectos específicos de la esclavitud en el ámbito local, comparando sus similitudes y diferencias con las de otras regiones, e insertarla en el contexto histórico 
general del país. Sin embargo, pienso que el no poder atender al todo no invalida los resultados parciales como los aquí presentados.

La estructura del texto está dividida en dos partes: la primera, una descripción detallada de los documentos y la información que ofrecen, incluso sobre la población blanca, para mejor evaluar el contexto regional del que se está hablando; y la segunda, dirigida a la ejemplificación de los temas derivados del anterior, pensando en que, si bien, la perspectiva estrictamente local carecería de interés para alguien ajeno, podría contener alguna información metodológica aprovechable, de ahí las aclaraciones detalladas sobre ellas.

\section{LAS FUENTES}

En 1988, por iniciativa de algunos especialistas en archivos y estudios africanos de la UNESCO, se procedió a la elaboración de una Guía de Fuentes para la historia de África, de la esclavitud negra y del negro en la sociedad actual. La idea era localizar y ubicar las fuentes que pudiesen informar y facilitar futuras investigaciones sobre el tema, en todos los países donde la esclavitud se practicó. El resultado final en Brasil fueron dos volúmenes de referencias documentales publicados ese mismo año. ${ }^{1}$ Años más tarde, y como consecuencia de esa primera experiencia, por iniciativa personal elaboré el catálogo, aún inédito, de los archivos cartorários o notariales en que se basa este artículo.

Forman un universo aproximado de 450 documentos manuscritos, provenientes de los libros (algunos sin numeración) del "Cartório do Primeiro Oficio de Notas”, equivalente a la Notaría Pública núm. 1, y del antiguo "Cartório do Segundo Oficio de Notas", ya extinto, cuyo acervo fue incorporado al anterior.

Así, el acercamiento a los afrodescendientes se hizo a partir de esas fuentes, pero con el apoyo bibliográfico pertinente para algunas prácticas de la vida cotidiana. La idea fue complementar los datos

${ }^{1}$ Guia Brasileiro de Fontes para a História da África, da Escravidão Negra e do Negro na Sociedade Atual, 2 tomos, Río de Janeiro, Frente Arquivistica, Coordenação do Arquivo Nacional, Departamento de Imprensa Nacional, 1988.. Mi participación como voluntaria en el apartado correspondiente a Araxá fue mi primer contacto con el tema que, sin embargo, no fue objeto de mis investigaciones inmediatas. 
del censo y ejemplificarlos con casos extraídos de los inventarios y testamentos, que suelen ser más proficuos a ese respecto. Porque, tanto los censos, como los documentos notariales pueden ser bastante lacónicos, una vez que siguen los protocolos formales establecidos para cada modalidad, pero si son interrogados correctamente y complementados con otros pueden arrojar informaciones sorprendentes.

Los notariales son formados por escrituras de compra-venta, donación e hipoteca de esclavos o "partes" de esclavos; escrituras de "alforria" o libertad; y escrituras de "perfilhamento" o reconocimiento de paternidad, éstas, evidentemente, en número bastante reducido. Contienen el nombre de los vendedores, donadores o hipotecados y el de los compradores, donatarios e hipotecarios, así como el nombre, edad, "calidad", registro, oficio y precio del esclavo. En algunos casos hay datos y cláusulas que los tornan peculiares.

Los del censo aquí usado son formados por las "minutas" o planillas con los datos individuales de cada persona: edad, color y ocupación, así como las tablas finales que contabilizan la población, constituida por blancos, esclavos y afrodescendientes libres.

Finalmente, los inventarios, que incluyen los testamentos abiertos a la muerte del testador, y que son más detallados pues contienen, por un lado, la relación de los herederos, con nombre, edad, estado civil y cónyuges; los resultados de la descripción, cuantificación y evaluación del patrimonio del fallecido; las deudas por pagar o los "dineros" por recibir; el reparto legal de los bienes entre los herederos; y por otro, para suerte de los historiadores, las demandas y acciones legales de los inconformes.

Por ejemplo, el inventario de Desiderio Mendes dos Santos, blanco, contiene el testamento por el que nombró a su esposa, Josefa Pereira da Silva, parda, "testamentaria" o albacea y heredera de su patrimonio personal. Pero contiene también los autos de la demanda que interpuso contra ella su suegra, a fin de anular su matrimonio e inhabilitarla como heredera. ${ }^{2}$

${ }^{2}$ Rosa Maria Spinoso de Montandon, Josefa Pereira "mulher parda... ”. Raça e cor na história de uma mulher anónima. Araxá, século XIX, Evidência. Olhares e pesquisa em saberes educacionais, Instituto Superior de Educação, UnIARAXÁ, año 2, núm. 2, 2006, 137-148. 
Documentos como esos son invaluables porque permiten conocer representaciones y prácticas sociales que de otra manera no se entenderían. Éste, en particular, me permitió saber que Josefa era afrodescendiente y con ello entender el racismo implícito en la concepción estética de Dona Beja, el mito representativo de Araxá. ${ }^{3} \mathrm{Su}$ puestamente una "cortesana”, eufemismo para las prostitutas de lujo, a quien se describe blanca, rubia y de ojos claros, pero sin pruebas documentales de ello. Pero, principalmente, me llevó a entender que en la literatura sobre ella, Josefa apareciera siempre como prostituta barata, sin la menor base documental que lo confirmara. Concluí que el objetivo fue servirle de contrapunto a Dona Beja, en el proceso de limpieza racial a que fue sometida para su mitificación. ${ }^{4}$

Finalmente, los testamentos, que contienen los últimos deseos del fallecido, con instrucciones, donaciones y a veces hasta confesiones. Tenemos el caso de Ana, que fue liberada por su dueña atendiendo a los últimos deseos del marido, que "confesó" en su lecho de muerte, ante el notario y testigos, que era el padre, conforme quedó registrado en la escritura de libertad. ${ }^{5}$

\section{Araxá en el CENSO PROVINCIAL}

Y hablar de esclavitud negra en el Brasil requiere de cuidados, ya que frecuentemente se tiende a generalizarla. Para comenzar, las dimensiones continentales del país presuponen un universo geográfico bastante diversificado, sin hablar de las distintas formas de producción desarrolladas en cada región y que produjeron prácticas esclavistas diversificadas. Eso contribuiría para validar estudios demográficos simplificados, como el que aquí se propone, ya que -sabemos- el incremento de las historias locales y regionales ha sido precisamente una de las mejores consecuencias de esos estudios.

${ }^{3}$ Rosa María Spinoso de Montandon, Dona Beja. Desvendando o Mito, Universidade Federal de Uberlandia, 2005.

${ }^{4}$ Rosa María Spinoso de Montandon, "Dona Beja: racismo e preconceito na concepção estética do mito", ArtCultura. Revista do Instituto de História da Universidade Federal de Uberlândia, MG. vol. 7, núm. 10, enero/junio de 2005, 111-121.

${ }^{5}$ Escritura de libertad. Cartório do $1^{\circ}$ Oficio de Notas de Araxá, libro 9, hoja 2v, 29/11/1853. 
En el caso de Araxá, estamos hablando de uno de los municipios que forman la microrregión del Alto Paranaíba, integrante del antiguo "Sertão da Farinha Podre", hoy "Triángulo Mineiro", en el Estado de Minas Gerais. ${ }^{6}$

Históricamente, la región comenzó a desarrollarse económicamente hacia las últimas décadas del siglo XvıII, con base en la agricultura y la ganadería, destinadas respectivamente al consumo doméstico y al mercado interno, con todo lo que eso pudiere significar para la configuración de una sociedad latifundista, patriarcal y esclavista, estrechamente vinculada con la tierra. En tal modelo, los vínculos familiares, el estatus socioeconómico y la representatividad política de un individuo estaban condicionados por la posesión de la tierra, incluso porque sólo los propietarios estaban habilitados para votar y ocupar escańos en los cabildos municipales.

El marco histórico inicial de Araxá podría situarse hacia 1792, ańo de la demarcación de la "Sesmaría do Barreiro", de donde salió la parcela de tierra donada para formar el patrimonio exigido por la Iglesia para la creación de nuevas capillas. En este caso, una dedicada a Santo Domingo de Guzmán, en cuyas tierras surgió y se desarrolló el poblado.

La "freguesía" de São Domingos do Araxá fue elevada a cabeza de juzgado en 1811, a villa en 1831 y a ciudad en 1865 , y por lo menos hasta las primeras décadas del siglo xx, el ayuntamiento local seguía pagando a la parroquia un tributo anual de un conto de réis (un millón de reales) por haberse desarrollado la ciudad sobre los terrenos de la iglesia.

${ }^{6}$ Estado que integra la Región Sudeste del Brasil, junto con São Paulo, Rio de Janeiro y Espirito Santo. El Triangulo Mineiro o la "nariz" de Minas Gerais, es una amplia faja territorial de forma triangular, entre los ríos Grande y Paraníba, que al juntarse forman el Río Paraná.

${ }^{7}$ Sesmaría: concesiones de tierra con el objetivo de incrementar la ocupación territorial en Brasil. Las dedicadas a la ganadería medían 3 leguas de largo por una de ancho y 1 x 1 las dedicadas al "garimpo" o explotación minera. La legua medía 2,400 m. En una investigación preliminar realizada en los archivos del poder judicial local, catalogué 111 sesmarías ubicadas en el Juzgado de Sáo Domingos do Araxá, en el periodo entre 1772 y1821, año en que fue extinto tal sistema de concesiones. 
Y fue precisamente al año siguiente a la instalación del primer ayuntamiento y su consecuente elevación a villa, que se realizó el censo provincial que dio para São Domingos do Araxá, sede del municipio, la cifra de 2,848 habitantes, entre blancos y de color, éstos divididos genéricamente en pardos y "pretos", en condición de libres y esclavos. Es evidente que tales datos deben ser vistos con restricciones, ya que, como lo admitían ante el presidente de la provincia los propios encargados del censo, el número podía no ser exacto "por falta de haber entrado algunos individuos que componen un número tal vez mayor que este que representa el mismo mappa”. La razón alegada era que no todas las personas habían tenido "buena voluntad" de colaborar, lo que debe entenderse que se referían no sólo a los responsables por recopilar las informaciones, sino también a los que las daban. No debe ser difícil imaginar la desconfianza que debía despertar entre los labradores y sus familias tal interrogatorio sobre sus vidas y propiedades, considerando la actitud desconfiada, supuestamente propia de la gente del campo, y asociada en especial a los de Minas Gerais, que en adelante llamaremos "mineiros".

Por otro lado, el censo estaba basado en los datos colectados en la villa, donde se suponía que la mayoría de la gente, incluso los labradores, tenía residencia fija, aunque en la relación final de habitantes no aparezcan muchos de los que de hecho la tenían. Es seguro que cuando los encuestadores recogieron los datos, estas personas se encontraban en sus haciendas, en donde vivían la mayor parte del tiempo. Eso porque, por lo general, quedaban bastante alejadas de la villa en función de las propias dimensiones de las mismas. El registro de los "labradores" que si aparecen en el censo, sólo comienza a partir del fuego número 71 .

De hecho, gran parte de esos araxaenses sólo abrían sus casas en la villa durante las festividades religiosas, cuando llegaban las familias en verdaderas caravanas, que incluían esclavos domésticos y recuas de mulas cargadas con los productos de fabricación casera, que serían vendidos o intercambiados en la feria. Así, para el tema de la esclavitud que aquí nos ocupa, Araxá puede representar un microcosmos de la región en que se ubica, donde los planteles de esclavos solían girar alrededor de 30 "piezas". De acuerdo con el censo, hacia 
la década de 1830, los blancos ahí eran minoría, 929, contra 1,092 afrodescendientes libres y 827 esclavos. $^{8}$

En las tablas numéricas, los libres eran clasificados generalmente como "pardos", que sumaban 1,012, contra sólo 80 "pretos" o negros. Esto podría sugerir un criterio valorativo en el que la libertad matizaba el color, ya que, en estas listas, no encontramos ningún esclavo pardo. Ahora, también podía ser consecuencia de la antigüedad de la condición de libertos, tratándose como pardos a los nacidos libres o que lo eran desde hacía varias generaciones, mientras que los que la hubiesen adquirido recientemente, por compra o donación, seguían siendo tan negros como cuando eran esclavos. Hay que recordar que los criterios fenotípicos de identificación estaban sujetos a una serie de variables no escritas, que la mayoría de las veces quedaban a cargo de la percepción de la persona que hacía el registro, en este caso, el encuestador.

Un caso que así lo sugiere es la ya mencionada Josefa Pereira da Silva quien, en el ya mencionado proceso de anulación matrimonial, interpuso una demanda judicial en contra del abogado de su suegra, que se refirió a ella como "mujer parda", lo que la ofendió mucho. Alegaba ella que tal apelativo era innecesario y humillante, y citaba un determinado decreto, seguramente remanente de la legislación portuguesa, que consideraba delito el uso de términos peyorativos para las personas de color. Josefa efectivamente lo era, pero era libre, hija legítima de padre blanco y madre de color, por lo que alegaba que, si bien no podía ser considerada una "europea", era con mucho honor "ciudadana brasileña". Todo indica que lo peyorativo del término pardo que la humillaba no se debía al color en sí, sino a que la remitía a la condición esclava de sus ancestros, y que no era la negritud sino la esclavitud la causa de su disgusto. ${ }^{9}$ Ahora, la cuestión aquí es, que si un abogado podía incurrir en tales equívocos, qué no decir de las personas improvisadas en encuestadores que recopilaron los datos del censo de población aquí usado.

8 "Mappa populacional da Provincia de Minas Gerais", 1832. Seção Colonial, caixa 13. Arquivo Público Mineiro. Belo Horizonte, MG.

${ }^{9}$ Rosa Maria Spinoso Arcocha, "Josefa Pereira mulher parda"... op. cit., p. 145. 


\section{LOS DATOS DEL CENSO}

Para una mejor idea, presentamos los campos que formaban las planillas y que eran: De los "fuegos"; Habitante; Calidad; Condición; Edad; Estado (civil); Ocupación.

La palabra "fuego" era alusiva a hoguera, de la que deriva hogar y sinónimo aquí de residencia. Eran numeradas a partir del cuadrilátero central, en este caso la plaza de la parroquia principal, la Igreja Matriz de São Domingos, de donde iban avanzando hacia la periferia. Como en los centros urbanos de la América española, cuanto más próximas las residencias de las sedes de los poderes civiles y religiosos mayor el estatus social y económico de sus dueños, por lo que no deja de ser significativo que, en Araxá, los dos primeros fuegos numerados tuvieran como cabeza a dos afrodescendientes, Sotero Ribeiro Rosa, negociante, pardo, que vivía en el primero con la esposa y 10 esclavos, y su tía Josefa Pereira da Silva, que residía en el número dos. De la misma forma, también es comprensible que, tomando como base el número de esclavos que tenían, los comerciantes más importantes aparecieran en los fuegos ubicados en el área central.

El campo "habitante" se refería al cabeça de casal o jefe de familia, que por regla general era hombre, aunque de vez en cuando aparecieran algunas mujeres para quebrarla. Más o menos 29 en Araxá, 14 blancas y 13 pardas. Y ese resultado "mas o menos" es consecuencia de la precaria legibilidad de los documentos, que impide contabilizarlos correctamente, ya que en las tablas numéricas finales datos como éste no fueron contabilizados.

Por lo general, las mujeres cabeza de familia eran viudas, como dońa Anna Rosa de Jesús, blanca, de 34 años, residente en el fuego número 397, con tres hijos entre 9 y 12 años, y que administraba un patrimonio de 21 esclavos. Aunque también había excepciones. Ese era el caso de doña Anna Jacinta, que era soltera, blanca, de 32 años, y cabeza de una familia formada por ella, su madre también blanca y 8 esclavos, todos residentes en el fuego número 6, o sea, enfrente de la plaza principal. Doña Anna Jacinta sabemos que tuvo dos hijas, la segunda aún no nacida en esta época, pero si la mayor que, sin embargo, no aparece en el censo. Probablemente ya debía estar casa- 
da y residiendo con el marido en la hacienda, motivo por el cual no fueron contabilizados en el censo.

En el caso de las pardas, tenemos el de la misma dońa Josefa Pereira da Silva, viuda, sin hijos, residente en el fuego número 2 en compañía de 8 esclavos y 4 criollos libertos; o de dońa Anna María, que vivía en el fuego número 92, con sus 6 hijos: un sastre, un zapatero, dos costureras, dos menores y una esclava, Thereza, de 60 años.

Y aquí es interesante resaltar el contraste entre el estatus concedido a los esclavos en el censo, en tanto seres contabilizados como parte de la población total del país, mientras que en los inventarios y testamentos eran cuantificados y evaluados como parte del patrimonio de un ciudadano, pudiendo ser vendidos, comprados, intercambiados, donados, alquilados e hipotecados de la misma forma y junto con los bienes raíces, o el ganado vacuno y equino. Antonio de Souza Pereira, por ejemplo, hipotecó sus esclavos Rita cabra, de 26 años; Carlos cabra, de 11; María cabra, de 9; y Antonio pardo, de 7, "junto con 8 cabezas de ganado". ${ }^{10}$

"Calidad" era un campo aplicado a todos, inclusive a los blancos, que eran registrados como tales en el censo, mientras que los esclavos y afrodescendientes, aparecían como "africano(a)", "criollo(a)", “mulato(a)", "pardo(a)" y “cabra”. Ese campo solía ser más explícito en las escrituras notariales, que indicaba también la procedencia. Entre las más frecuentes estaban Africano, Angola, Benguela, Calunda, Congo, Mina y Mozambique.

Por ejemplo, parte del "plantel” o esclavonía del sargento mayor Joaquín Correia da Silva estaba formada por Pedro "de nación angola”, de17 ańos; Manuel africano, de 25; Alesandra cabra, de 26; Gabriel mulato, de 36; João "congo", de 30, Claudina "conga", de 32; Casilda criolla, de 9; Francisca cabra, de 12; Felicia criolla, de 7; Sergio criollo, de 5; Bernardo criollo, de 5; Luciana criolla, de 4; Josefina criolla, de 9; y David criollo, de 2. Formaban todos un "lote" que fue hipotecado en 1845 por 6 contos de réis. ${ }^{11}$

${ }^{10}$ Escritura de hipoteca. Libro 6, hoja 20. 07/01/1841. Cartório do $1^{\circ}$ Ofício de Notas. Araxá, MG.

${ }^{11}$ Idem. Libro 7, hoja 1v. 29/04/1845. 
La misma designación por etnia u origen podía indicar las aptitudes o especialidades de oficio, lo que, dependiendo de la región, podía incidir en su valor de mercado. Por ejemplo, se dice que en Brasil fueron los esclavos los que enseńaron a los portugueses las técnicas para la extracción del oro que ya usaban en sus lugares de origen. Ciertamente que eso debía incidir en su mayor valoración en las regiones en donde se practicaba tal actividad, que no era el caso de Araxá, pero a la que la provincia debía su nombre: Minas Gerais.

"Condición” era un campo aplicado sólo a las personas de color, que podían ser cativos cuando esclavos, o forros cuando libertos. Sobre tal rubro se hablará más adelante en un apartado especial, así como sobre las formas de adquisición de la libertad.

"Estado civil" era aplicado, tanto a los blancos, como a los de color que fuesen libres o libertos, pero raramente a los esclavos. Y aquí nuevamente nos encontramos ante un contraste entre los datos demográficos y las prácticas cotidianas, ya que los archivos parroquiales están repletos de registros de bautizo y matrimoniales de esclavos. Así, en el terreno religioso, el esclavo era tenido como un ser con alma, cuya salvación espiritual era responsabilidad de su dueño, quien procuraba bautizarlo y casarlo "como Dios manda", aunque en la vida cotidiana fuese visto y tratado como un animal de trabajo. La propia Iglesia poseía esclavos y nada impedía que los blancos los apadrinaran. Es más, como pudimos verificar en otros trabajos, ${ }^{12} \mathrm{el}$ apadrinamiento de esclavos fue otra de las formas usadas por los blancos para estrechar y fortalecer las relaciones de amistad y parentesco con objetivos patrimoniales: facilitar el acceso a la tierra o reforzar su posesión.

Por otro lado, el disfraz de padrino/ahijado podía servir para encubrir paternidades ilegítimas o disfrazar parentescos inconvenientes con los esclavos. Senhorina Ribeiro da Conceição, por ejemplo, dio la libertad a Laureano Ribeiro, "su ahijado y esclavo", sin precio ni condición, ${ }^{13}$ lo que no sería extraño si el ahijado no apare-

\footnotetext{
${ }^{12}$ Véase, por ejemplo, Rosa María Spinoso de M., Dona Beja. Desvendando o Mito.

${ }^{13}$ Escritura de libertad. Libro 7, hoja s/n, 17/07/1846.
} 
ciera en la escritura de libertad con el apellido de la madrina y fuese el único entre los casos consultados en igual condición.

Para Gilberto Freire, en el Brasil colonial, el prejuicio de la ilegitimidad fue menos fuerte que el de color, lo que habría facilitado los matrimonios y la ascensión social para los hijos naturales, "cuando blancos o mulatos claros". ${ }^{14}$ En los archivos notariales consultados encontramos sólo tres escrituras de perfilhamento o reconocimientos de paternidad de hijos de padres blancos y madres esclavas: dos del teniente coronel Francisco Antonio de Araujo, quien en 1855 legitimó a los cinco hijos, de 9 a 1 año, que tuvo con su esclava María criolla; ${ }^{15}$ y la de su hija Rosaria, que tuvo con María, y que bien podría tratarse de la misma. ${ }^{16}$ El otro fue Pedro Affonso de Almeida, quien legitimó a Miguel, de 15, que tuvo con Luciana criolla, "esclava de su madre" ${ }^{17}$ La idea era asegurar a los hijos el acceso por herencia al patrimonio paterno, e impedir que éste se perdiera por la ausencia de herederos.

"Ocupación". Este último campo es uno de los más interesantes por su potencial informativo, aun cuando los registros en muchos casos se encuentren ilegibles. No fue posible contabilizar todos, pero entre los que se pudieron hacer llaman primero la atención los clasificados como mentecaptos, a veces varios en una misma familia; los "enfermos" y el caso de un "ciego", que si bien no eran precisamente ocupaciones suponían limitaciones que los impedían de tenerla.

En el caso de los hombres, la mayoría de los blancos aparece como lavrador (172 contra 60 de color), seguidos de lejos por los negociantes (32 contra 5 de color), o las dos cosas juntas, para el caso del propietario individual de la mayor esclavonía (31 esclavos), que si bien comparada con la de otras regiones puede parecer reducida, para el caso de Araxá era considerable. Eso porque como se sabe, la ganadería requería menos mano de obra que, por ejemplo, la plan-

${ }^{14}$ Gilberto Freyre, Casa-grande \& Senzala. Formação da família brasileira sob o regime da economia patriarcal, 35a ed., São Paulo, Record, 1999, 447.

${ }^{15}$ Escritura de perfilhamento. Libro 9, hoja 33, 17/08/155. Cartorio do $1^{\circ}$ Ofício de Notas. Araxá, MG.

${ }^{16}$ Idem. Libro 18 , hoja 76, 11/04/1887.

${ }^{17}$ Idem. Libro 10, hoja 161v, 16/11/1861. 
tación de café, de caña o los garimpos, como se llamaban los sitios dedicados a la explotación de oro y piedras preciosas.

En el caso de los de color, las ocupaciones predominantes en Araxá eran jornalero (22, contra 3 blancos) y carpintero (14 contra 6 blan$\cos )$, que aquí se refiere a los que trabajan la madera para la construcción civil, y cuyo número se explica por el modelo de arquitectura residencial de la región, que presenta coberturas de teja que requieren maderamiento. Entre los blancos figuraban un boticario y 2 talabarteros y, como excepción, 2 sastres y 4 zapateros, ocupaciones dominadas casi siempre por los afrodescendientes. No aparece el término fazendeiro o hacendado para el ganadero, y todo indica que el de labrador, que significa literalmente trabajador de la tierra, los incluía.

En los casos de los 2 jornaleros y los 2 zapateros blancos que aparecen en los registros, éstos fueron colocados al final de la lista de dependientes, después de los esclavos y donde solían ir los mentecatos. Eso llama la atención porque, lo normal en el orden de las planillas, era que primero aparecieran los titulares de la residencia, marido y mujer, seguidos por los hijos; los agregados de color libres; y los esclavos. Los blancos aquí comentados no debían ser parientes y no eran esclavos, pero formaban parte de la familia extensa porque trabajaban para la misma.

En relación con las mujeres, sólo aparece una labradora, doña Joaquina Teodora, blanca, viuda de 50 años, viviendo con 4 hijos, 11 esclavos y un zapatero blanco, ya que en los otros 5 casos ( 4 pardas y 1 blanca), ellas fueron clasificadas como roceiras, lo que significa pequeñas labradoras, y debían serlo.

Por lo general, las haciendas ganaderas de la región formaban verdaderas células autosuficientes que producían de todo, o casi, con una agricultura dirigida al consumo doméstico y el excedente al comercio local. Tal supuesto es reforzado por las listas de compras que constan en los inventarios anexos a los testamentos, en los que aparecen los productos adquiridos en los almacenes de la villa, en donde los hacendados solían mantener cuentas abiertas que saldaban anualmente con el producto de la venta del ganado. Tales listas indican poca variedad de productos, destacándose la sal, los utensilios domésticos y las herramientas de cobre o hierro; seda y artículos 
de mercería, ya que casi todo lo demás necesario para la subsistencia era producido en la propia hacienda.

Y eso nos lleva al tema de la ocupación femenina, que raramente aparece en el censo, a no ser en algunos casos de viudas y solteras, generalmente pobres, o ni tanto. Doña Joana Cándida, por ejemplo, blanca, de 45 años, no debía serlo, ya que aparece como panadera y al frente de su fuego (número 111) con dos hijos solteros y 7 esclavos. Ya Thereza, también blanca, pero soltera aparece, curiosamente, como la única engomadeira o especialista en almidonar y planchar ropa. Lo curioso de su caso es que en el imaginario de la esclavitud doméstica, esa era una tarea de las mucamas o esclavas personales de las señoras.

Ya en el caso de las mujeres pardas y negras libres, el tópico ocupación fue indicado con más frecuencia y casi siempre relacionado con alguna de las especialidades domésticas. Destacan por el número, las costureras ( 15 entre pardas y criollas, contra 10 blancas); las hilanderas (14 contra 5 blancas); las "farinheiras" (5 pardas), especialistas en hacer "polvilho" o fécula de yuca, que también es rayada y tostada para hacer la farinha. En el caso de las rendeiras o especialistas en encajes, la proporción era de 4 blancas contra 2 pardas.

Y la incidencia de costureras, hilanderas y tejedoras en el censo podría explicarse porque, entre los principales productos artesanales de la región, fuese en las residencias urbanas o en las haciendas, estaban los tejidos de lana (principalmente colchas y mantas), fabricados en los telares domésticos que eran generalmente manipulados por mujeres. Hacia la década de 1870, la calidad de tales productos ya era reconocida y las noticias habían sobrepasado las fronteras regionales, como lo indica la solicitud de algunas muestras que le hizo la Secretaría de Negocios de la Marina a la legislatura municipal de Araxá, para saber sobre la posibilidad de abastecer al ejército. La respuesta fue negativa, con la alegación de que la ciudad no contaba con mano de obra suficiente para producir el volumen requerido. ${ }^{18}$

${ }^{18}$ Archivos de la Câmara Municipal de Araxá. Hasta el momento de mi investigación, la documentación no estaba catalogada ni los archivos organizados, motivo por el cual no se dan más referencias. 


\section{LA CONDICIÓN ESCLAVA Y LA CUESTIÓN PATRIMONIAL}

Hasta aquí, la idea fue mostrar un panorama poblacional de Araxá a partir de los datos arrojados por el censo, ejemplificados con los de los archivos notariales para, enseguida, comentar algunas prácticas asociadas al cautiverio. Prácticas de las que no estuvieron exentos los afrodescendientes, integrados ya en una sociedad blanca y sus prácticas vigentes. Así, no faltan ejemplos locales de afrodescendientes esclavistas. Uno de ellos fue José Pereira Bom Jardím, para no repetir el de la ya tantas veces citada Josefa Pereira. Bom Jardim fue carpintero, erigido por la memoria local a personalidad histórica, como responsable de la construcción de la parroquia de San Sebastián, hoy uno de los símbolos de la religiosidad popular y el monumento arquitectónico más antiguo de la ciudad. ${ }^{19}$ Como su esposa e hijos, Bom Jardín era pardo, propietario de 5 esclavos, 3 africanos y 2 criollos. Y tenemos también el caso de Basilio Magno, que aparece en el censo como el único letrado, criollo y dueño de 11 esclavos; y aún el de Joana Pereira de 40 ańos, criolla y único caso femenino de comerciante, con dos esclavos africanos de 20 y 18 años.

La fortuna y el prestigio en esta sociedad se medían no sólo por el número de hectáreas de tierra, de inmuebles o de cabezas de ganado, sino también por los esclavos. Éstos podían ser una muestra visible de fortuna, por lo que formaban parte de las dotes que los padres otorgaban a las hijas casaderas, de los regalos que los abuelos hacían a sus nietos cuando nacían, o los padrinos a sus ahijados cuando los bautizaban, por lo que su posesión sobrepasaba el aspecto financiero. De que era una buena inversión no hay duda, pero también era un asunto de prestigio y estatus social.

En relación con la cuestión patrimonial, como mercancía un buen esclavo podía llegar a tener más valor que la tierra. Por ejemplo, en 1864, 203 alqueires $^{20}$ de la "Fazenda Boa Vista", fueron ven-

19 "Carpinteiro" y "carapina” son sinónimos y designan a quien trabaja con madera en la construcción civil, en cuanto que el "marceneiro" fabrica muebles.

${ }^{20}$ Unidad de medida de tierra equivalente a 4.84 hectáreas en Minas Gerais, Rio de Janeiro y Goiás, y a 2.42 en São Paulo. 
didos por dos millones, 169 mil réis, $(\mathrm{R} \$ 2: 169,000)$, al mismo tiempo que Ignacio criollo, un esclavo de 22 ańos, llegó al precio de dos millones y 100 mil réis $(\mathrm{R} \$ 2: 100,000) .{ }^{21}$ Ciertamente, fue por eso muy usada la modalidad en la compra/venta de "partes" de esclavos, en la que cada socio adquiría una o varias partes del mismo, quien trabajaba para cada uno el tiempo proporcional al de las adquiridas. Esas partes podían ser vendidas o hipotecadas cuando el socio lo desease, lo que era bastante frecuente. En 1862, el teniente coronel Francisco Antonio de Araujo vendió por 625 mil reales "una parte" de la esclava Josefa criolla, de 23 años, mientras que Manuel José Tavares Sobrinho recibió 288 mil 246 reales "por 3 partes" de su esclavo Jerónimo pardo, de 29; y 300 mil por " 5 partes" de Lúcia criolla, de 25 ańos, a quien acompañaban sus hijos Adan, de 11, María de 10, Pedro de 9, y Jerónimo de $1 .^{22}$

En relación con la valoración del esclavo, ésta podía depender de innumerables factores, como la edad, la procedencia, la especialidad, o su capacidad productiva y reproductiva, entre las más comunes. Si bien, tratándose de mercancía humana no se excluyen las de carácter subjetivo y personal, que al final también formaban parte de las condiciones del mercado. La precaria situación financiera o la urgencia del dueño por venderlos podrían hacer bajar su valor, así como podían elevarlo las dificultades para adquirirlos, provocadas muchas veces por las medidas legales tendientes al control del tráfico.

Leyes como las de 1826 y 1831, contra el comercio de esclavos; la "Euzébio de Queiroz", de 1850, que lo equiparaba a la piratería; y aún las del "Vientre Libre" y de los "Sexagenarios", que consideraban libres a los recién nacidos y a los mayores de 60 años, podían elevar el valor del esclavo, aunque en realidad estuviesen más orientadas hacia las buenas relaciones con Inglaterra que hacía una política antiesclavita.

21 "Réis" es plural de real, y "conto de réis", equivalente a mil mil réis o un millón de reales.

${ }^{22}$ Libro 12, hojas 81v a 106. Sartorio do $1^{\circ}$ Oficio de Notas de Araxá. 


\section{Mercado de esclavos y LIBERTAdes}

Hacia finales del periodo esclavista ya se había creado un fondo destinado a pagar parte de las libertades. "Por cuenta del Fondo de Emancipación según cuota distribuida al municipio”, fueron liberados en Araxá, José criollo, de 14 años, matriculado con el número 4,065, Rosa parda, engomadeira, de 20, con el número 4,064 y Manoel, de 26, con el número 4,023. Asimismo, los tres contribuyeron con recursos propios para completar el precio de su libertad. Y ciertamente que tales fondos y cuotas fueron creados pensando más en garantizar a los dueños el pago que a los esclavos la libertad.

En términos generales y con base en las escrituras consultadas, hacia la década de 1840 fue posible percibir una tendencia al aumento en el precio de los esclavos, que se acentuó en la década siguiente, llegando a su pico entre 1860 y mediados de 1870 . A partir de 1875 comienza a constar en las escrituras el número de la matrícula expedido por las oficinas de hacienda municipal, lo que significa un mayor control fiscal, con el inicio de una caída paulatina que se va acentuando hacia 1885 , cuando ya no se encuentra ninguno con valor superior a los 900 mil reales. Esa tendencia se mantiene hasta 1887, año de la ultima escritura de compra/venta de esclavos en esta notaría. Se trataba de Marciana preta, soltera, hija de María hilandera, número 1,177 en la matricula antigua y 3,045 en la nueva Coletoria de Araxá. ¿Precio? 400 mil reales.

Otro factor de valoración debía ser la escasa moneda circulante, lo que hacía del esclavo una buena inversión en tanto "producto" de más fácil comercialización que la tierra o que el ganado, al que había que hacer crecer y engordar, además de esperar la época propicia para colocarlo en venta. A menudo, los negocios se pagaban con esclavos, con tierra o con ambos. Así, el millón y 400 mil reales que Francisco de Paula do Nascimento pagó en 1866 a Ursulina Carneiro Belmira por su esclavo Joaquín criollo, de 26 ańos, fue en tierras de una hacienda.

Para pagar sus deudas, Custodio Rodríguez de Rezende hipotecó en 1869 , por 10 millones de reales, su esclavonía formada por 16 esclavos. El valor seguramente habría podido ser más alto si ellos no 
estuvieran en tan mal estado. Clemente criollo, de 45 años, estaba "rendido en la ingle", lo mismo Manuel criollo, de 40, y Marcos africano, de 54, que además estaba "manco de un pie". Herculano mulato, de 8, estaba "ciego de un ojo", en cuanto que la cocinera Juliana africana, de 60, estaba "con una herida en la coronilla". ¿Era resultado del maltrato?, evidentemente que sí, pero también de la ruina financiera de su dueño, que lo llevó a deshacerse incluso de su cocinera. Porque si había alguna especialidad de trabajo esclavo y un territorio en el que la edad, en vez de defecto era cualidad, esa era la cocina. Las cocineras desarrollaban sus propias recetas y fórmulas culinarias que casi siempre guardaban de memoria, lo que significaba que se iban junto con ellas. Además, las especialidades culinarias y la fabricación de conservas y compotas caseras era una de las formas más socorridas entre las mujeres para reforzar los presupuestos familiares. ${ }^{23}$ De ahí que cuando un hombre tenía que vender hasta la propia cocinera era porque la bancarrota había llegado literalmente hasta la cocina.

Porque un esclavo también tenía la ventaja de que podía ser alquilado cuando sus dueños necesitaban dinero y sin tener que deshacerse definitivamente de él. Y existía además el sistema "al gano", modalidad de trabajo esclavo en los centros urbanos, mediante la cual éste era obligado a aportar a sus dueños una determinada suma diaria o semanal. ¿Cómo lo hacían? Eso era problema de ellos. Generalmente era vendiendo cosas o alquilándose en trabajos para terceros. Una modalidad que contradice el imaginario tradicional del esclavo prisionero y encadenado, trabajando de sol a sol bajo el látigo o el chicote, lo que no disminuye la perversidad del sistema. Los esclavos "al gano" circulaban más o menos libres y sueltos por las ciudades, con la anuencia de sus dueños a los que interesaba únicamente el dinero que les redituaban, sin importar cómo lo obtuvieran.

Así, los hombres podían emplearse como cargadores; estibadores, cuando se trataba de puertos; zapateros; carpinteros; sastres;

${ }^{23}$ La región sigue siendo conocida por la calidad de sus dulces y conservas en almíbar de fabricación casera. 
vendedores ambulantes de agua o comida; o en cualquier servicio pagado para el que fuesen contratados. Las mujeres se podían alquilar en las casas de terceros como costureras, bordadoras o hilanderas, o realizar tales labores en la casa de sus dueños, bajo pedido. Igualmente circulaban por las calles vendiendo los productos de su especialidad culinaria; frutas de la estación e, incluso, prostituyéndose.

Y ciertamente que eso facilitaba, por un lado, la creación de redes sociales y de ayuda entre ellos y, por otra, la adquisición de la suma necesaria para pagar su libertad, ya que las ganancias así obtenidas podían exceder la cuota establecida por sus dueños, quienes difícilmente podrían controlarlas con exactitud. En el caso de las mujeres, no por casualidad, los especialistas consideran que en los centros urbanos o en las regiones más al sur, dedicadas a la producción agropecuaria de subsistencia, fueron más favorables para que tuvieran una cierta posición de igualdad frente a los hombres y de autonomía frente a sus amos. "Las ciudades y villorrios - dice una autora- permitieron que las mujeres cautivas conquistaran una independencia que no poseyeron nunca sus colegas rurales". ${ }^{24}$

Eso debe responder, en parte, a una duda que siempre surge cuando se habla de libertades compradas, ¿cómo obtenían el dinero los esclavos?, quedando aún por explicar cómo lo hacían los de las haciendas ganaderas, donde el sistema de gano aparentemente no existía. Si bien que para estos casos estaba el "pago con servicios", como fue con Mariana criolla, cuya libertad fue pagada con el trabajo de su marido en la hacienda de su amo. Y ciertamente estaba el producto de la venta de lo que sembraban, ya que en algunos casos los amos les permitían hacerlo en pequeñas parcelas.

Todo eso podría pensarse para el caso de Araxá, en donde aún no existen estudios a ese respecto, como ningún otro sobre la esclavitud, pero donde seguro apuntarían para el sistema de gano como explicación para el número de esclavos carpinteros, jornaleros, zapateros, herreros, costureras e hilanderas que figuran en las listas, y de

${ }^{24}$ Eni de Mesquita Samara y Horacio Gutiérrez, "Mujeres esclavas en el Brasil del Siglo XIX", en Historia de las Mujeres 4. El Siglo XIX, trad. Marco Aurelio Galmarini, México, Taurus, 2001, 677. 
mujeres y hombres de color libres, viviendo de esas ocupaciones. Sin hablar de las mujeres solas que aparecen sin ocupación definida. Por cierto que los 4 músicos que constan en el censo eran pardos, así como lo era el único pintor, Manoel Antonio Vieira, el único sacristán y el único curtidor de cuero.

\section{LIBERTADES REGALADAS, LIBERTADES VENDIDAS}

Sobre las formas de conceder la libertad, algunos autores suponen la existencia de lazos afectivos entre amos y esclavos, con base en los motivos alegados para ello en los documentos notariales. Tales documentos hablan de libertades que se decían gratuitas mediante frases como "por los buenos servicios prestados" o "por el mucho amor que le tengo". Sin embargo, habría que considerar que tales frases eran fórmulas protocolares para efecto documental, más que expresiones de afecto.

Podría pensarse en algún tipo de dependencia simbiótica que algunos amos desarrollaban con sus esclavos, ya que no era raro que crecieran juntos por haberlos recibido desde que recién nacían. Era común que los abuelos o padrinos dieran de regalo a sus nietos o ahijados un "negrillo" o una "negrilla" para acompañarlos de por vida. Por eso, no es de extrañar que, entre las cláusulas condicionantes para la concesión de la libertad, las más frecuentes fueran las que obligaban a los exesclavos a seguir viviendo o sirviendo a su antiguo dueño hasta la muerte de uno o del otro.

Pero pensar en relaciones afectivas requiere de cautela. En primer lugar, una relación afectiva presupone dos lados, por lo que cualquier cosa que se diga al respecto, en este caso sólo podrá tener uno, el de los señores. De lo que los esclavos sentían poco o nada quedó registrado. Bueno, a no ser en los autos de los procesos criminales, por delitos cometidos por ellos o contra ellos, y que son bastante elocuentes, pero no precisamente por hablar de amor. Por otro lado, habría que considerar la naturaleza y calidad de un afecto basado en la condición sojuzgada de uno de los miembros, que era tenido como propiedad por el otro. Eso llevaría a pensar por analogía en el afecto hacia una mascota o caballo, el semental o la vaca 
más productivos, a los que hay que cuidar porque representan inversión y porque maltratarlos daría perjuicio, pero a los que se puede vender cuando necesario.

Claro que la convivencia constante, la docilidad, la adulación, la lealtad o incluso las paternidades o parentescos podrían granjear a los esclavos el afecto de sus dueños, sin que eso significase que éstos dejasen de verlos como lo que eran, esclavos, de hecho y de derecho. Y eso ya presupone una forma de afecto bastante peculiar, para decir lo mínimo.

Una prueba de ello sería el escaso número de escrituras de perfilhamento o reconocimientos de paternidad de los hijos tenidos con las esclavas, únicas evidencias efectivas de ese afecto, en la forma de garantía patrimonial. Otra serían las mismas condiciones que les eran impuestas para la concesión de la libertad, cuando los dueños se la daban supuestamente regalada. Es posible que muchas de las libertades así concedidas a niños hayan sido resultado de paternidades o parentescos no asumidos. Como lo sugiere la escritura mediante la cual Narciso Rodríguez da Silva le dio la libertad a "mi criollito José, de 4 años". Fue liberado junto con Crescencia de uno, y María conga de 28, probablemente la madre de ambos. ${ }^{25} \mathrm{Y}$ en este caso, lo de criollito estaría más afín con el apelativo genérico para los afrodescendientes que para su "calidad", ya que si nuestras sospechas estuvieran confirmadas, él sería mulato. Otro ejemplo es Antonio pardo, de 6 años, que recibió su libertad por su dueña al juzgar "que su sangre circula por mis venas".

Sobre las condiciones y precios de la libertad, de las 217 escrituras de libertad consultadas, contabilizando 248 esclavos liberados individualmente, o en grupo pero mediante una sola escritura, en 110 no se establece ninguna condición o precio, lo que contabiliza 159 esclavos libertos de esa forma. Sin embargo, muchas veces las condiciones ya habían sido cumplidas con creces.

Anna criolla, por ejemplo, recibió su libertad en 1823, por los "buenos servicios" prestados a su dueño, pero también por su fecun-

${ }^{25}$ Escritura de libertad. Libro 6, hojas 100v y 101v, 17/07/1844. Cartorio do 1 Oficio de Notas. Araxá, MG. 
didad, "por haber producido cinco crías que estoy poseyendo"; ${ }^{26} \mathrm{o}$ Francisca Benguela, que la obtuvo "en cumplimiento de la promesa que le hicieron sus señores por haber criado 10 hijos" ${ }^{27}$ En ambos casos, queda la sospecha de que cuando las dos mujeres obtuvieron la libertad ya debían encontrarse en una edad avanzada o en la que eran inútiles como reproductoras, y que al dárselas los dueños también quedaban libres de su manumisión.

Por eso, la ausencia de cláusulas condicionantes no significaba que no hubiera condiciones, ya que podían haber quedado como acuerdos verbales y previos entre los exesclavos y sus antiguos dueños, de los que frecuentemente jamás lograban desvincularse. Estudios al respecto apuntan que después de la abolición gran número de exesclavos, principalmente en la zona rural, seguían viviendo y trabajando con sus antiguos dueńos, de los que a veces adoptaban el apellido.

Entre las 21 escrituras de libertad condicionada consultadas, llaman la atención algunas fórmulas protocolares. Anna María de São José, por ejemplo, decía estarle dando la libertad a su esclava Thereza, "por el mucho amor que le tengo, y fidelidad con que me ha servido y haber criado a mis hijos, además de la molestia grave que padece", pero aún así, con la condición final de acompañar a su dueña "hasta la sepultura". ${ }^{28}$ Por su parte, Alejandro criollo obtuvo su libertad supuestamente gratuita, pero a condición de que comprara otro esclavo de su mismo precio para ocupar su lugar. Las más frecuentes eran las que obligaban al esclavo o a la esclava a seguir viviendo y sirviendo a sus dueños o a alguno de sus herederos por un determinado plazo, o hasta la muerte de uno u otro. Domingos, de 22 o 23 ańos, hijo de Ana criolla, recibió su libertad con la condición de seguir viviendo con su dueño, prestándole servicios gratuitamente, ${ }^{29}$ o Joana criolla, que la recibió con "la condición de servir a su dueña hasta la muerte".

¿Pero la muerte de quién? habría que preguntarse. ¿De la ama o de la exesclava? Bueno, en el caso de José cabra, de 9 años, eso quedó

${ }^{26}$ Idem. Libro s/n, hoja 33. 29/12/1823.

${ }^{27}$ Idem. Libro s/n, hoja 21v. 11/06/1823.

${ }^{28}$ Idem. Libro 4, hoja 74v, 28/12/1831.

${ }^{29}$ Idem. Libro 7, hoja 25v, 06/04/1846. 
bien claro, ya que estuvo "obligado a servir a su dueño hasta la muerte de éste", ${ }^{30}$ pero en el caso de Francisco Benguela, liberto con la condición de "servir a su señor en cuanto vida tuviere", ciertamente que se refería a la del esclavo, ya que recibió la libertad a la edad de 60 años. ${ }^{31}$ Lo que nos lleva justamente a otros posibles motivos para las concesiones de libertad, que confirmarían las fórmulas protocolares y desmentirían la alegada caridad cristiana. Sospechamos que Emerenciana María de Jesús, que recibió la libertad "gratis y de limosna”, estaba entre esos casos ya que, curiosamente, en la escritura no se menciona su edad, dato que raramente se omitía. ${ }^{32}$ Debía ser mayor y por tanto improductiva.

Así, las pérdidas del dueño ante la improductividad del esclavo, causada por la edad avanzada, por las enfermedades o por las limitaciones físicas que dificultaban la venta, eran muchas veces solucionadas con la libertad. Aunque muchas veces la misma edad y muerte inminente de los dueńos, también podría llevarlos a actos de caridad cristiana con los que pondrían en día las cuentas con el Creador. Negociaban su salvación al precio o expensas de sus esclavos, a los que daban la libertad con esa incumbencia.

Hubo quien la recibió literalmente a cambio de la salvación del alma de su dueño, con la condición de trabajar para pagar sus funerales y misas. Jerónimo (58 años), fue uno de ellos, en cuanto que Antonio (22) fue libertado con la condición de trabajar para las hijas huérfanas de su dueña, hasta que ellas terminaran sus estudios, y con el producto de su trabajo mandar a rezar 10 misas por su alma. ${ }^{33}$ Otros de plano fueron dejados al cura como pago por las misas. Algunos recibían la libertad como herencia de sus amos, que así lo dejaban establecido en testamento, como en los casos de Antonio Benguela y Maria criolla; pero otros la heredaban junto con las deudas, como Vicente criollo, liberado "gratuitamente" por su dueña con la condición de quedarse con ella "hasta la muerte de esta y pagar las deudas que ella dejase".

\footnotetext{
${ }^{30}$ Idem. Libro 9, hoja 57v, 18/08,1856.

${ }^{31}$ Idem. Libro 9, hoja 8v. 17/04/1853.

${ }^{32}$ Idem. Libro s/n, hoja 17, 10/05/1823.

${ }^{33}$ Idem. Libro 16, hoja 16, 29/06/1880.
} 
Sobre las libertades con precio, con base en las 57 escrituras consultadas, podría decirse que éste generalmente obedecía al mercado y a los factores que incidían en la compra/venta. Sin embargo, sospechamos que en la mayoría de las libertades vendidas a bajo precio y sin que conste la edad de los favorecidos, se trataba de gente mayor, ya que como se vio, su precio podía caer conforme la edad avanzaba. En relación con las oscilaciones en la valoración de la libertad, se puede decir que también obedecía a factores semejantes a los de las anteriores, dependiendo de la época.

Así, la década de 1860 siguió siendo la de mayor alza en el mercado y cuando la libertad de Miguel (14 años), por ejemplo, costó 1 millón y 500 mil reales; la de Ignacio (7 años), 800 mil; la de Baldoino (5 años), 650 mil; y la de Máximo (3 años), 400 mil. Todos pardos e hijos de Luciana criolla. ${ }^{34}$

Las formas de pago podían efectuarse al contado (aunque raras), en pagos, o a plazos predeterminados, pero muchas veces con condiciones. Alexo criollo (14 años), y Angelo criollo (12 años), obtuvieron su libertad por el precio de 100 mil reales el primero y $80 \mathrm{mil} \mathrm{el}$ segundo, pero con la condición de continuar sirviendo a su dueño y a los hijos de éste "hasta su muerte". Por su parte, Francisco Congo tendría que esperar la muerte de su dueña para pagar los 700 mil de su libertad a sus acreedores. Al final, aún quedaría por entender que a pocos años de la Ley Áurea aún existiera un floreciente mercado de libertades, lo que indicaría lo ajenos que debían estar los esclavos de Araxá sobre las campańas abolicionistas y sus gestiones previas.

\section{PARA CONCLUIR...}

El estudio de la esclavitud negra en Araxá está apenas en su inicio, por eso, en las notas preliminares se presentó este texto como un ejercicio tentativo, más que conclusivo, bajo el supuesto de que nada absoluto existe en la historia. Sus asertivas son fugaces; valen hasta el momento en que aparezcan otras negándolas o, ¿quién sabe?, confirmándolas; ampliándolas o complementándolas. Hasta el momento

${ }^{34}$ Idem. Libro 10, hoja 46. 11/02/1860. 
en que se produjo este articulo, podía decirse que era el único al respecto y por lo mismo no existía bibliografía disponible para este lugar. La lectura de la documentación se realizó con base en estudios de los especialistas sobre otros lugares. Así, dudas y temas podrán surgir, impedidos de agotar en una sola publicación. Ejemplo de ello son algunos comentarios - que agradezco-, de colegas que leyeron el texto previamente, sobre el tema de los esclavos al gano, y que sugirieron compararlos con los de otros centros urbanos, como Río de Janeiro, sobre el que ya existen estudios, a fin de establecer sus diferencias o semejanzas con los de Araxá.

Realmente, mucho más habría que decir sobre la esclavitud y los que la vivieron en "carne propia”, a quienes, como se habrá podido notar, insistí en llamar por su nombre y seńalar su edad y calidad. Esta última no porque así la considere, sino porque entre la parquedad de los datos sobre ellos, éste era uno de los que raramente faltaba. Así, si Josefa se ofendió por ser llamada parda, no fue mi intención repetir tal ofensa, sino más bien enfatizar la perversidad de una institución que permitía hacerlo.

Para concluir, espero que este ejercicio de lectura e interpretación de los datos e informaciones arrojados por los documentos oficiales pueda servir, si no como modelo, al menos como motivación para otros en la misma línea y en la misma temática.

\section{Fuentes}

Archivos Notariales. "Cartórios do $1^{\circ}$ y $2^{\circ}$ Oficio de Notas". Araxá, MG. Archivos de la "Fundaçáo Cultural Calmon Barreto de Araxá". MG. Archivos del Poder Judicial. "ForumTito Fulgêncio". Araxá. MG. Archivo Público Mineiro. Belo Horizonte, MG.

Memória do Judiciário Mineiro. Belo Horizonte, MG.

BibliografíA

Buarque de Holanda, Aurélio, Novo Dicionário Aurélio, 2a ed., Río de Janeiro, Nova Fronteira, 1986.

Chalmoub, Sydney, "Medo Branco de Almas Negras: Escravos, Li- 
bertos e Republicanos na cidade do Rio", en Escravidão, Revista Brasileira de História, São Paulo, vol. 8, núm. 16, 1988, 83-105. Freyre, Gilberto, Casa-grande \& Senzala. Formação da família brasileira sob o regime da economia patriarcal, 35ª ed., São Paulo, Record, 1999.

Geulen Christian, Breve Historia del racismo, Madrid, Alianza Editorial, 2010.

Guia Brasileiro de Fontes para a História da África, da Escravidão Negra e do Negro na Sociedade Atual, 2 tomos, Río de Janeiro, Frente Arquivistica, Coordenação do Arquivo Nacional, Departamento de Imprensa Nacional, 1988.

Hunt, Lynn, La invención de los derechos humanos, Barcelona, Tusquets, 2009.

Melo e Souza, Laura de, org., História da vida privada. Cotidiano e vida privada na América portuguesa, São Paulo, Companhia das Letras, 1997.

Santos Soares, Luis Carlos, "Os Escravos de ganho no Rio de Janeiro do século XIX", en Escravidão, Revista Brasileira de História, São Paulo, vol. 8, núm. 16, 1988, 107-137.

Mesquita Samara Eni de y Horacio Gutiérrez, "Mujeres esclavas en el Brasil del Siglo XIX", en Historia de las Mujeres 4. El siglo XIX, Traducción de Marco Aurelio Galmarini, México, Taurus, 2001, 677.

Spinoso de M., Rosa Maria, Dona Beja. Desvendando o Mito, Uberlândia, EDUFu, 2005.

"Dona Beja. Racismo e preconceito na concepção estética do Mito", en ArtCultura, Revista do Instituto de História da Universidade Federal de Uberlândia, MG, vol. 7, núm. 10, 2005.

Spinoso Arcocha, Rosa Maria, "Josefa Pereira mulher parda”... Araxá, século XIX”, en Evidência, Olhares e pesquisa em saberes educacionais, UNIARAXA, Instituto Superior de Educação, año 2, núm. 2, 2006, 137-148.

FECHA DE RECEPCiÓN DEL ARTículo: 4 de agosto de 2007

FECHA DE ACEPTACIÓN Y RECEPCIÓN DE LA VERSIÓN FINAL: 2 de junio de 2008 